\title{
Smart Transformer using Advanced Metering Infrastructure (AMI) and Advance Sensor Infrastructure (ASI)
}

\author{
Geeta Velhal $^{1}$, Avani Pujara ${ }^{2}$, Vaishali Velhal ${ }^{3}$, Dr S.M.Bakre ${ }^{4}$, Dr V.Muralidhara ${ }^{5}$
}

\begin{abstract}
Transformer is one of the sensitive components of the smart grid. The transformers already installed, will be in service for next 25 years .Very few transformers have ability to sense the parameters like voltage, current, and temperature. The next generation of transformers will require implementation of remote monitoring of a system parameters and wide range of transformers. Online transformer monitoring using advanced metering infrastructure (AMI), Advance Sensor infrastructure (ASI) is necessary for efficient operation of the smart grid. An AMI system can be effectively used as a low-cost distribution transformer monitor. The safety of the transformer plays a vital role in smooth operation of a smart grid. Dissolved gas analysis, use of vegetable oil-based dielectric coolants, ensures reliability and safety respectively of the transformer operation. Now a days many transformer manufacturers are incorporating the real time monitoring of the temperature, pressure, vacuum especially for step up transformers. Real time monitoring system consists of embedded system, GSM modem, mobile-users and GSM networks and sensors installed at transformer site. Features of Solid State Transformer (SST), Bidirectional Intelligent Semiconductor Transformer (BIST) for smart grid applications are discussed in this paper. Also, the different ways for improving efficiency of the smart grid by ensuring the safety of the transformer are focused.
\end{abstract}

Keywords: Advanced metering Infrastructure (AMI), Solid State Transformer (SST), Bidirectional Intelligent Semiconductor Transformer (BIST).

\section{INTRODUCTION}

Transformers installed already in distribution system are having single function, to increase or decrease the level of voltage. Once the conventional grid becomes smart and topology changes in distribution system, bidirectional transformer would be needed to improve voltage profile and to solve power quality issues. Online monitoring of transformer will help utility to detect fault in real time.

Using advanced meter infrastructure, distribution transformer monitoring can be done in real time [6]. This can provide insight for taking action well in advance before transformer fails.

The monitoring systems currently used has some problems and deficiencies, like

1)Conventional transformer can detect a single parameter

like voltage, current or power.

2) Testing speed is not fast

3) Real time detection is not there

We need a distribution transformer which is smart enough to monitor all the parameters at a time and with very good speed, this will help to identify overall health of transformer; which ensures safety of transformer before any serious fault occurs. A sensor is a device, which responds to an input quantity by generating a functionally related output usually in the form of an electrical or optical signal. A sensor's sensitivity indicates how much the sensor's output changes when the measured quantity changes [4]. Sensors can be installed at transformer site which reads and measures the physical quantity from the distribution transformer and converts it into analogue signal, it can sense load current, ambient temperature, winding temperature, oil temperature, level of oil, humidity of oil ,dissolved gases in oil, partial discharge etc. Also fire hazards occurring at power transformer and interconnecting transformer installations are the matter of serious concern. These installations are prone to fire because of several reasons such as internal faults, overheating, high order harmonics, failure of dielectric, lightening etc. This may result into loss of valuable assets.

Moreover such types of incidences may cause fatal or nonfatal accidents to human being or stray animals. It has been observed on number of occasions that there is a sudden blasting of porcelain bushings. The pieces of porcelain are scattered in the switchyard with high velocity and cause damage to nearby equipments in the switchyard. Therefore, it is highly desirable to protect transformers from fire hazards.

Online monitoring of transformer consists of GSM modem, mobile users GSM network and sensors [7].

In this paper working of nitrogen injection system is discussed to understand smart way of operation of transformer under fire. Under occurrence of fire the smart system of protection will quench the fire quickly and it will save transformer from severe damage. Online transformer monitoring using advanced metering infrastructure (AMI), Advance Sensor Infrastructure (ASI) is necessary for efficient operation of the smart grid.

An AMI system can be effectively used as a low-cost distribution transformer monitor [8]. There are two principal ways to achieve this objective. The first calls for the installation of a bellwether meter on the secondary output of each device to be monitored. The bellwether meter will take advantage of the AMI infrastructure to return actual transformer loading and performance data. Such a solution may introduce a potentially significant extra cost at each transformer location. 


\section{DISSOLVED GAS ANALYSIS}

DGA is most important part of any transformer maintenance which involves study of dissolve gases in oil of transformer.

The most important test that can be done on the liquid insulation of a transformer is Dissolved Gas Analysis (DGA). This test can give an early indication of abnormal behaviour of the transformer oil. DGA test analyses the type and quantity of gases that are dissolved in the transformer oil. DGA results would allow us to identify the type of fault occurring in a transformer in service.

Generally the gasses found in the oil in service are hydrogen (H2), methane $(\mathrm{CH} 4)$, Ethane (C2H6), ethylene $(\mathrm{C} 2 \mathrm{H} 4)$, acetylene $(\mathrm{C} 2 \mathrm{H} 3)$, carbon monoxide (CO), carbon dioxide (CO2), nitrogen(N2) and oxygen $(\mathrm{O} 2)$.[5] Manual DGA can be done in three steps

- Oil sample extraction

- Extraction of the gases

- Gases separation \& measurement

Online DGA it is possible to increase operating safety while simultaneously reducing costs. Online DGA can be used for maintenance and asset life management, for early fault detection to enhance or monitor performance.

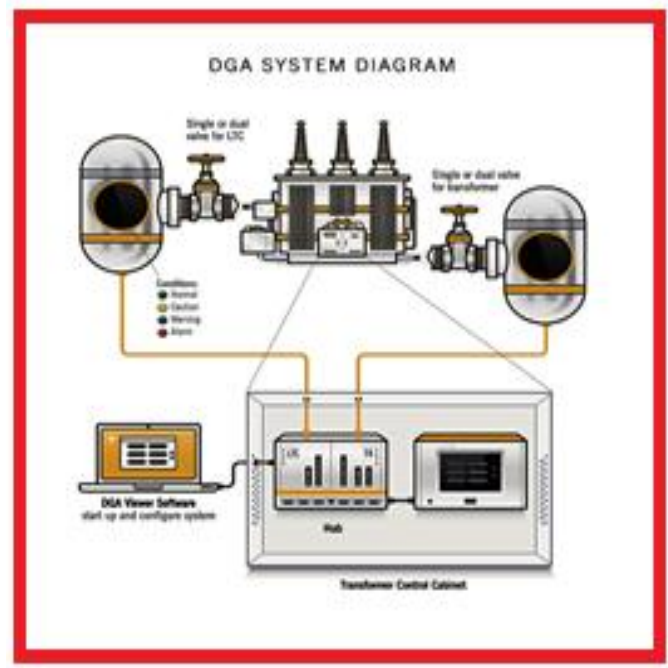

FIG.1. DGA SYSTEM [1]

\section{PALM OIL ENSURES SAFETY OF TRANSFORMER}

Liquid insulating material used in the transformer also acts as a coolant. Since late nineteenth century, petroleum oil has been used in electrical equipment [3].Mineral oil is widely used because of its affordable cost and good dielectric properties. But petroleum reserves are going to deplete in near future; so we need to think of alternative for it. When the fault occurs in the transformer e.g. rupture of tank, oil leakage, the petroleum oil ,which is poorly biodegradable, will be major environmental challenge for the nature. In Malaysia, mineral oil is used in transformer as the insulating medium. Because of the environmental awareness raised rapidly, fully biodegradable vegetable oils are used in the transformer [2]

Breakdown of the insulation in transformer is caused because of the moisture content .Water leads degradation of the insulating material.NurSyamimi Murad, N. A. Muhamad conducted an experiment, To study moisture absorption level for commercialized palm oil-based transformer oils and came to the conclusion that ,compared to the other palm oil and mineral oil, PFAE (palm fatty acid ester oil) oil had the highest breakdown voltage even when the moisture content were increased up to $2500 \mathrm{ppm}$ water added. It is due to the characteristic that PFAE has greater electrical resistance to electrical breakdown. Due to this, PFAE can be considered to replace mineral oil in future completely [2].

\section{NITROGEN INJECTION SYSTEM}

The main parts of the system are briefly discussed below-

1. Sensors- The sensors are usually provided at the top side of transformer tank. These units work as temperature transducers. The temperature of transformer oil is sensed by these sensors. Any abnormal rise in temperature due to fire hazards is detected by these sensors.

2. Valves- The valves are provided at three locations - a. between conservator and breather $b$. on oil drain pipe and c. at nitrogen cylinder. In the event of fire hazards, the opening and closing of these valves takes place automatically.

3. Pipelines- Basically two pipelines are provided, one for oil evacuation and the other for nitrogen filling.

4. Control box- The control box receives signals from sensors and accordingly sends command to operate the system. In this paper, it is proposed to connect control box to the existing tulip communication system through RJ11 and Modbus.

5. Oil Pit- It is an underground pit below the soil in which the small quantity of oil is drained from transformer tank.

6. Outdoor cubicle- The outdoor cubicle is provided near transformer installation. It comprises of nitrogen cylinder and mechanism for operating the system.

7. Indoor Cubicle- The indoor cubicle is installed in the control room. It is connected to the system through a control cable. It comprises of fire switch, glass cover, hammer, LED indicators, Fire alarm indicators etc.

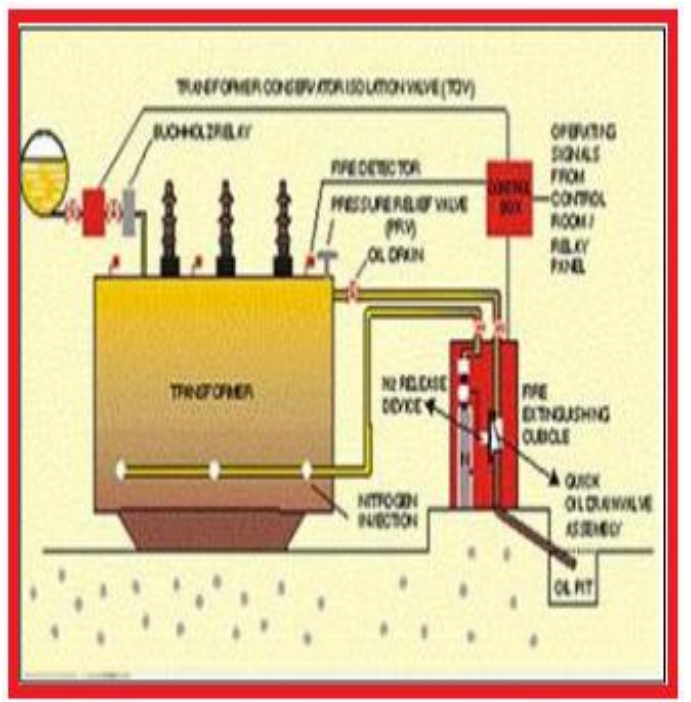

FIG.2. NITROGEN INJECTION SYSTEM

The overall working of fire injection system is as described below. Whenever there is an occurrence of fire 
hazards, obliviously there is rise in temperature. This Load Voltage Regulation temperature rise is detected by the sensors as shown by Protection against Overload \& Short Circuit square packets in Fig. The sensors inform abnormal Operates on Distribution Voltage Level condition caused because of rise in temperature, to the No Fire Hazard / Contamination control box. In response, the control box performs Small size and light weight following three actions in a sequential manner.

The valve provided near buccholz relay is closed. This stops circulation of transformer oil between conservator and main tank.

The Oil drain valve is opened and a small quantity of oil (usually $1 \%$ ) is taken from top of the tank to the underground pit as shown in figure 4. This forms a small gap at top of the transformer tank.

Now the nitrogen valve is opened so that the nitrogen gas is released from cylinder and gets injected inside the transformer tank. The nitrogen gas is injected at the bottom of tank. However, because of low density it goes up and fills the gap created by evacuation of the oil. The nitrogen quenches the fire immediately.

\section{V.SOLID STATE TRANSFORMER FOR BIDIRECTIONAL FLOW IN SMART GRID}

SST and BITS ensure safety in smart grid:

The solid state transformer is a power electronic device that replaces the traditional $50 \mathrm{~Hz}$ power transformer by means of high frequency transformer isolated AC-AC conversion technique, [5] This brings the promising advantages such as the power flow control, voltage sag compensation and fault current limitation. The basic diagram of a SST is given in Fig. Isolation is achieved through SST. The grid voltage is converted into a higher frequency AC voltage through the use of powerelectronics based converters to be applied to the primary side of the transformer. The opposite process is performed on the transformer secondary side to obtain an AC and/or DC voltage for the load.

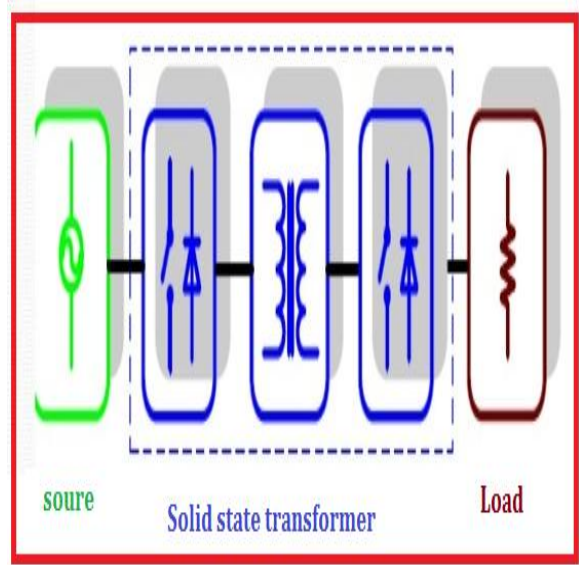

FIG.3. SOLID STATE TRANSFORMER

For smart grid application bidirectional semiconductor transformer is used to ensure safety. Following diagram of BIST consists of high-voltage high-frequency ac/dc converter, bidirectional low-voltage $\mathrm{dc} / \mathrm{dc}$ converter, and hybrid-switching dc/ac inverter. [6]

Functionalities and features of bidirectional transformer: Voltage Harmonics / Sag Compensation Outage Compensation

Protects Power System from Load Disturbance
Bidirectional power flow

Input to output isolation

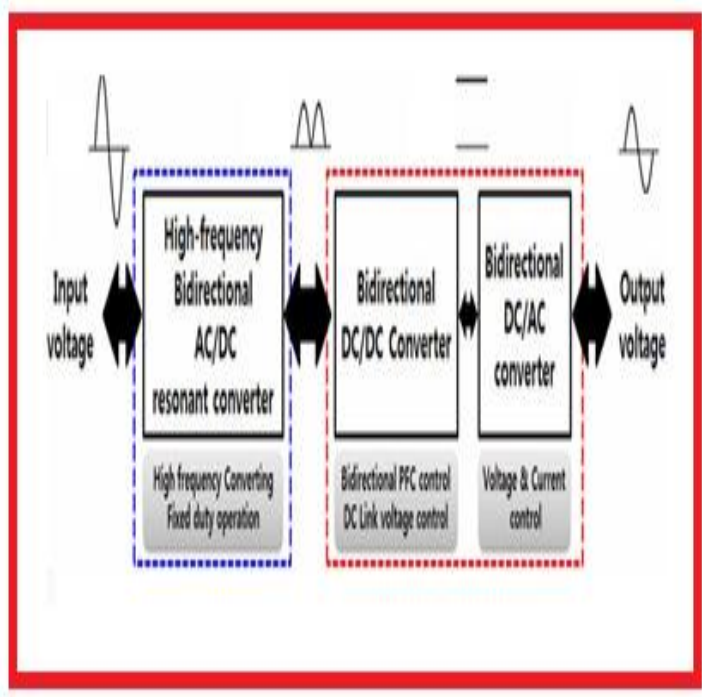

FIG. 4. BIDIRECTIONAL TRANSFORMER

\section{GSM COMMUNICATION}

The temperature acquisition module will sense the transformer temperature. The data processing module mainly has microcontroller and its peripheral Circuits. It processes the data and sends it to control module. When the temperature goes high, out of the limit then the control module will send the temperature data and alarm signal to user by SMS [10].

User receives the data by SMS then starts the cooling system fan. GSM transceiver module is a link between embedded system and user GSM network. The server is attached to GSM modem and it sends SMS to mobile users containing various parameters of distribution transformer [6] [9].

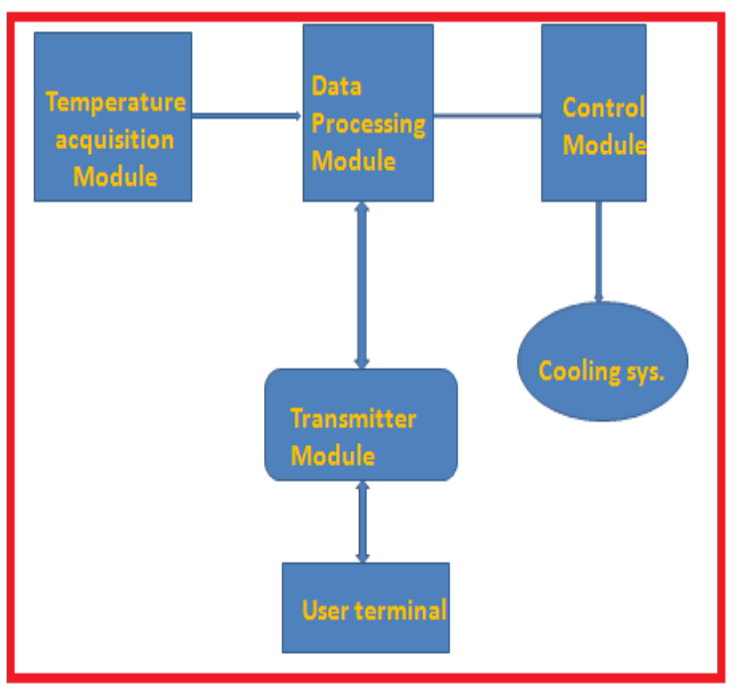

FIG.5. OVERALL STRUCTURE GSM COMMUNICATION OF TRANSFORMER 


\section{CONCLUSION}

Online monitoring using Sensors, Advanced metering infrastructure, and GSM Communication, transformer safety can be ensured in smart grid. It also serves the purpose of fast fault analysis and improves not only overall health of transformer but the entire distribution system as well.

With the implementation of Nitrogen injection system, Dissolved Gas Analysis and using Bidirectional transformer it is easier to get safe and smart transformer for upcoming smart Distribution System.

\section{ACKNOWLEDGEMENT}

Authors are grateful to Jain University, Bangalore for providing required research facilities and encouragement.

\section{REFERENCES}

[1] www.electricalenergyonline.com

[2] 2013 Annual Report Conference on Electrical Insulation and Dielectric Phenomena

[3] Wilson, A.C.M., Insulating Liquids: Their Uses Manufacture and Properties. 1980, IEEE Electrical and Electronic Materials and devices

[4] www.electrical4u.com

[5] Xiao-hui Cheng, Yang Wang," The remote monitoring system of transformer fault based on the internet of Things", 2011 International Conference on Computer Science and Network Technology

[6] Velhal, G. ; Pujara, A. ; Bakre, S.M. ; Muralidhara, V.On progress of communication infrastructure for fault location and ABT metering,IEEE 2014

[7] Avani Pujara , Geeta Velhal , Dr S.M.Bakre , Dr V.Muralidhara, A Review on Smart Grid in India, International journal of innovative research in electrical, electronics, instrumentation and control engineering, Vol. 3, Issue 3, March 2015

[8] Dr.S.M.Bakre,,Nakul Bakre "Object Oriented Approach for Sensing Measurement Communication and Control of Data using Numeric Meters", March 2012

[9] Hahn Tram, "Technical and operation considerations in Using smart metering for outage management", IEEE 2008.

[10] Zhang Luhua, Yi Zhonglin, Yuan Ruiming,Zhou Hui, Yin Qingduo "Effects of Advanced metering Infrastructure on Relatons of power supply and Application in smart Grid," IEEE 2010.

\section{BIOGRAPHIES}

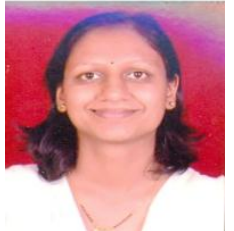

Velhal Geeta Vilas, Graduated in Electrical Engineering from Government of College of Engineering, Karad, in 2004 and had her Master's degree from Bharati Vidyapeeth University, Pune. She is currently pursuing $\mathrm{PhD}$ from Jain University, Bangalore and she is with Trinity College of institute and Research, Pune as an Assistant Professor. Her teaching experience is six years. Her area of interest is Power System protection and smart metering.

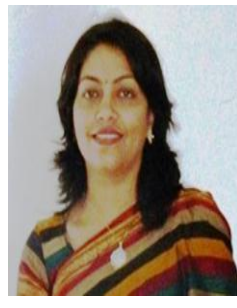

Avani Pujara has received her $\mathrm{BE}$ Electrical Engineering degree from Saurastra University. She earned her ME power system from Pune University and her teaching experience is 9 years. She is currently a research scholar at Jain University Bangalore. Her interest revolves around power system stability, smart grid and smart metering.

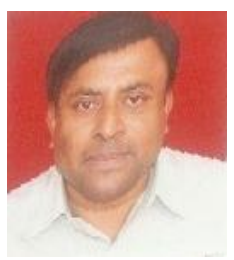

Dr. Shashikant M. Bakre completed his bachelor's degree in Electrical Engineering from Govt Engineering College Amravati ( Nagpur University ) , followed by master's degree in engineering from COEP (Pune University).He also completed MMS , master's degree in management from Pune University . Later, he completed his doctorate from Bharati Vidyapeeth Deemed University, Pune in the year 2011. $\mathrm{He}$ is the author of ten books on computer engineering .Some of his books are Computer Fundamentals, Computer Master, Build your own website , OOPS and Core Java, Object Oriented Analysis and Design and Supply Chain Management. He has published about 25 research papers. His research work is focused on applications of Information Technology in Power Quality . $\mathrm{He}$ is working with Maharashtra State Electricity Transmission Company as an Executive Engineer. He has worked at $400 \mathrm{KV}$ Lonikand SS , $400 \mathrm{KV}$ Jejuri Substation and Testing Communication Circle. At present, he is posted at Major Stores, Baramati .The areas of his research are mobile computing based applications .He is also working as visiting faculty at Symbiosis Institute of Business ,Pune.

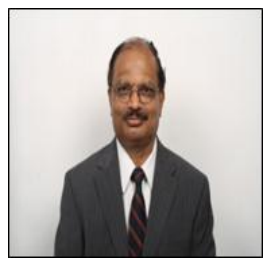

Dr. V.Muralidhara Obtained B.E. in Electrical Engineering, M.E. in Power Systems from Mysore University and $\mathrm{PhD}$ from Kuvempu University. During the years 1975, 1978 and 2012 respectively. He has started his teaching career from PES College of Engineering Mandya during 1976 and served there for 6 years and retired as Prof. and Head of EEE at BIT, Bangalore and served there for 31 years. At present serving the School of Engineering and Technology, Jain University Bangalore as an Associate Director. Published 4 papers in International conferences and one paper in International Journal as a part of the research work. His field of interest is Power Systems and High Voltage Engineering. 